\title{
IMAGENS DA RURALIDADE NO CATO MAIOR, DE CÍCERO, E NO DE RE RUSTICA, DE VARRÃO REATINO: QUESTÕES PRELIMINARES ${ }^{1}$
}

\author{
Matheus Trevizam* \\ Universidade Federal de Minas Gerais
}

RÉSUMÉ: Nous avons pour but, dans cet article, d'établir des comparaisons entre le traitement du thème de la ruralité dans le De re rustica, de Varron, et le Cato Maior, de Cicéron. Le premier texte nous présente une image de la vie et des pratiques rurales qui permet de l'inclure légitimement dans la catégorie de la littérature technique ancienne; il nous montre aussi, clairement, que les Romains du temps de l'auteur ne se consacraient pas toujours en "honnêtes paysans" aux activités de la vie rurale. On peut, en effet, y trouver beaucoup de concessions au luxe, ou à l'amour excessif du gain. Dans le Cato Maior de Cicéron, en revanche, la nature même d'un petit ouvrage qui appartient au groupe des écrits philosophiques de l'auteur et comporte de probables connotations consolatoires pour ceux qui redoutent les douleurs de la vieillesse, contribue à confiner la ruralité dans un rôle qui, quoique n'étant pas mineur, est assurément moins central que celui constaté dans le De re rustica. Pour ce qui est du dialogue cicéronien, en effet, les activités ou plaisirs (uoluptates) de la ruralité constituent, avec autres arguments possibles, la réponse aux griefs de l'inaction et de l'absence de toute jouissance, considérées comme le lot d'une vieillesse difficile: un sage (sapiens) vieillard ne cesse jamais

\footnotetext{
${ }^{1}$ Este artigo se insere como produção vinculada a nosso projeto de estágio pósdoutoral na Universidade de Paris IV/ La Sorbonne, como bolsista da CAPES e sob supervisão do prof. Dr. Carlos Lévy, a quem agradecemos pela solícita leitura e sugestões (título do projeto: "Imagens da ruralidade em fins da república romana o 'De re rustica', de Varrão reatino, e o 'Cato Maior', de Cícero"/ número do processo CAPES: 1501/11-9).

^matheustrevizam2000@yahoo.com.br
} 
de s'occuper de travailler la terre, dans un souci de production. Ils'engage dans cette activité avec joie, pour son bonheur même. En dernier lieu, nous essayons de montrer brièvementque la structure du Cato Maior, avec, fondamentalement, la partitio exposant d'abord les griefs contre la vieillesse (15), puis les réfutations de ces arguments (15ss.), et ne permettant pas de privilégier les aspects les moins riants de la ruralité: pour cette raison, Cicéron ne fait voir dans cette œuvre, par la "voix" littéraire du personnage de Caton l'Ancien, que les honnêtes et honorables bonheurs qu'est censée procurer l'agriculture.

MOTS-CLÉS: Littérature agraire latine; Cato Maior; Cicéron; Varron; ruralité.

\section{Introdução}

e s obras da Literatura latina a tematizarem o universo e as práticas agrárias congregam um corpus textual, por vários motivos, jamais negligenciável: inicialmente, fazemos atentar para o longo arco cronológico coberto por tais escritos nas letras da antiga Roma, o qual se inicia com o De agri cultura, de Catão Censor (séc. III/ II a.C.), passando pelo De re rustica varroniano mesmo, o Cato Maior e as Geórgicas de Virgílio, no séc. I a.C., antes de atingir o monumental tratado de Lúcio Júnio Moderato Columela (séc. I d.C.) e o Opus agriculturae, de Rutílio Tauro Emiliano Paládio (séc. IV a.C.). Além do fator de virem a representar, com tais expoentes, séculos da cultura romana, consideramos justificar-lhes o estudo o fato de serem elas, em tantos casos, cuidadas do ponto de vista da estrita arte compositiva: bastandonos neste quesito, no tocante às Geórgicas, evocar de passagem o juízo de atentos leitores como Sêneca ${ }^{2}$ e Michel de Montaigne, ${ }^{3}$ remetemonos, quanto ao De re rustica de Varrão e ao Cato Maior de Cícero, aos respectivos dizeres de René Martin e J. G. F. Powell:

Il suffit en tout cas d'examiner d'un peu près les trois livres pour se convaincre qu'ils n'ont pas été écrits à la hâte, mas qu'ils sont, au contraire, parmi les ouvrages les plus soignées et les plus

\footnotetext{
${ }^{2}$ Sêneca, em Epistulae Morales ad Lucilium, LXXXVI, 15, entende que o propósito de Virgílio em seu poema didático fora não ensinar a fazendeiros, mas deleitar o leitor.

${ }^{3}$ Cf. de Montaigne, M. Essais. Londres: Jean Nourse \& Vaillant, 1768. Vol IV, p. 102: Les "Géorgiques», quej'estime le plus accompli ouvrage de la poésie.
} 
minutieusement travaillés de la littérature latine. (...) Chacun des dialogues est en effet construit d'une façon extrêmement rigoureuse, avec un tel souci de diviser et de subdiviser chaque développement, que cette minutie a pu apparaître à certains critiques comme une maniaquerie sans fondement valable. ${ }^{4}$

Stylistically, this work is notable for its exuberance of metaphor and comparison, and for a quality of style in some passages (especially the section on agriculture $)^{5}$ that may be called lyrical. When Cicero himself described, in Orator 91ff., the 'middle' style whose aim was delectare, he might have been providing a prescription for the style of his own philosophical writings, in their less technical and more rhetorical portions (...): the chief qualities of this style are said to be suauitas, absence of contentio, richness of metaphor, and use of sententiae and loci communes. ${ }^{6}$

Ainda, apenas por tomarmos os dois "espécimes" sob nosso presente foco de análise, abordar um "mesmo" âmbito da vida e das práticas rurais não significa, nesse "indistinto" grupo comum de obras, apenas repetir ideias, formas de desenvolvimento temático (ou ideológico), papéis e relevância internamente concedidos a tal imaginário, mesmo quando um aspecto constitutivo importante, como o gênero literário da escrita, coincide. $\mathrm{Na}$ verdade, como adiante intentaremos demonstrar, os modos de existência das imagens da ruralidade no Cato Maior de Cícero e no De re rustica de Varrão revestemse de flagrantes especificidades, as quais consideramos cabíveis de serem explicitadas em que pese ao fato de sempre se ter aderido, ao vazá-las formalmente, à espécie dialógica Aristotelico more. ${ }^{7}$

\footnotetext{
${ }^{4}$ Cf. Martin, R. Recherches sur les agronomes latins et leurs conceptions économiques et sociales. Paris: Les Belles Lettres, 1971, p. 228-229.

${ }^{5}$ Grifo nosso.

${ }^{6}$ Cf. Powell, J. G. F. Introduction. In: Cicero. Cato Maior de Senectute. Edited with introduction and commentary by J. G. F. Powell. Cambridge: University Press, 1988, p. 23.

${ }^{7}$ Cf. Ruch, M. Le préambule dans les oeuvres philosophiques de Cicéron. Essai sur la genèse et l'art du dialogue. Paris: Les Belles Lettres, 1958, p. 40-42.
} 


\section{O De re rustica, de Varrão de Reate, e seus grandes aspectos modeladores do assunto agrário}

Como primeiro elemento distintivo da conformação das imagens da ruralidade numa obra como o De re rustica, sobretudo evidente no cotejo deste texto com o Cato Maior, ressaltamos o caráter técnico da exposição em que se enquadra. Com isso, pretendemos assinalar a própria constatação de, aqui, depararmos uma obra até certo ponto capaz de orientar para um fazer, mesmo que de modo geral ou não tão rigoroso quanto possível. ${ }^{8}$ Ora, constituem aspectos da tecnicidade expositiva de um tema dado justamente não poupar esforços com fins de tornar o dito, antes de mais nada, preciso comunicador da natureza do objeto (ou processo) sob a pena do escritor a abordá-lo.

Isso implica, muitas vezes, em certa "crueza" comunicativa, no sentido de que, diante da relação estabelecida entre o texto, o público e o escritor técnico, esse último tenda a privilegiar as exigências tipológicas do primeiro. Assim, traços como a devida atenção aos detalhes expositivos, a menor cautela com o "enfado" (ou choque) de leitores que idealmente se pressupõem interessados em todas as partes integrantes de uma dada arte/ téchne e a razoável sistematicidade ao tratála indiciam ao crítico o agenciamento de recursos com vistas a dotar uma obra de eficácia sob o aspecto da comunicação técnica.

Cremos pender o De re rustica varroniano para tal descrição, do ponto de vista da estrita tecnicidade agrária, por alguns importantes motivos. De início, caso tomemos para foco do comentário o conjunto dos três livros rústicos de Varrão, veremos descortinar-se a nossos olhos um todo realmente capaz de cobrir os principais ramos econômicos da ruralidade romana antiga: no primeiro, assim, o autor se ocupa da agricultura e da arboricultura, oferecendo tratamento panorâmico para práticas cronologicamente tidas, por alguns, como as segundas a

\footnotetext{
${ }^{8}$ Guiraud, em seu comentário a De re rustica III, adverte, assim, de alguns deslizes de Varrão autor técnico. Ele toma, no capítuloXVI, o termo erithace por uma espécie de material construtivo das abelhas; ora, em Plínio - Naturalis Historia XI, 17 -, ou mesmo em Aristóteles, sempre designou a matéria bruta do fabrico do mel (Varron. Économie rurale. Livre III. Texte établi, traduit et commenté par C. Guiraud. Paris: Les Belles Lettres, 1997, p. 101).

${ }^{9}$ Sobre as distintas configurações dos textos da literatura latina de algum modo comprometidos com o ensinamento, cf. Perutelli, A. Il texto come maestro. In: Cavallo, G. et alii. (org.). Lo spazio letterario di Roma antica. Roma: Salerno Editrice, 1989. Vol. I, p. 277-310.
} 
desenvolver-se no Lácio; ${ }^{10}$ o segundo, com a abordagem da "grande" e "pequena" criação animal, em atenção, dentre outros, aos domínios da suinocultura, da ovinocultura, da equinocultura e da pecuária bovina, introduz problemáticas, ao que tudo indica, desde o início presentes na vida material dos velhos habitantes de Roma: as lendas mesmas de fundação da Cidade, como nos lembra J.-N. Robert, fizeram de Rômulo ${ }^{11}$ e Remo camponeses criados por Fáustulo na humilde lida do pastoreio (não do cultivo).

O terceiro e último livro, enfim, privilegia de forma bastante ambígua um desenvolvimento econômico da ruralidade de especial sucesso em fins do século I a.C., quando o autor publicou o De re rustica: referimo-nos ao que ele próprio denomina uillatica pastio e designa, com efeito, a criação de animais menores (aves, peixes, caracóis, arganazes, abelhas...) nas cercanias das casas-sede dos antigos fundi rustici romanos (as uillae). Ora, não se conheceram até sua época, na Itália, outros usos tão centrais de aproveitamento produtivo do solo quanto aqueles a cuja descrição ele se dedica abrangentemente, nos termos vistos: teremos, pois, de esperar pelo século seguinte para assistir, no prefácio do livro X da obra agrária de Columela, ao que talvez sejam os inícios de um certo destaque da horticultura, ou cultivo comercial de ervas, flores e hortaliças. ${ }^{12}$

O exame do mesmo critério da sistematicidade técnica no interno de cada um desses livros rerum rusticarum também pode revelar-nos marcantes traços da concepção de escrita do autor. Um ponto, aqui, capaz de fazer ver como Varrão ainda busca apreender com ordem o essencial de cada "arte" (cultivo do solo, pecuária ou uillatica pastio, bem o vimos) diz respeito às tão (e eventualmente, mal $^{13}{ }^{13}$ comentadas divisões e subdivisões dos sucessivos tópicos-chave da obra: em alguma medida

\footnotetext{
${ }^{10}$ Cf. Robert, J.-N. La vie à la campagne dans l'antiquité romaine. Paris: Les Belles Lettres, 1985, p. 83-84.

${ }^{11}$ Cf. Robert, op. cit., 1985, p. 82: On peut en effet envisager l'histoire des origines de Rome sous cet angle; un des conflits les plus importants qui éclate sous Romulus est la guerre contre Albe. Or les terres de Rome sont riches et celles d'Albe stériles. Mais Albe a des magnifiques pâturages tandis que la plaine romaine convient peu aux troupeaux, surtout avec la chaleur de l'été. Il en va de même avec la Sabine dont les contreforts sont encore aujourd'hui voués au pâturage.

${ }^{12}$ Cf. Praelocutio do livro X do De re rustica do autor, onde ele se dirige a Silvino a respeito (Columella. On agriculture. With an English translation by E. S. Forster and E. H. Heffner. Cambridge, Mass./ London: Harvard University Press, 1954. Vol. III).

${ }^{13}$ Cf., supra, nota 3.
} 
presentes em todos os livros, essas conhecem seu pleno desenvolvimento e exuberância no segundo, em cujos inícios se inscreve rígida grade temática, depois adotada para o encaixe de todos os sub-tópicos do trato dos animais. ${ }^{14}$ Em vez de apenas criticar o autor pela "gratuidade" desta estratégia construtiva de todas as três partes do De re rustica, preferimos, sob o viés da consideração do texto como legítimo representante técnico da literatura agrária romana, ver nela, além de intentos de cobrir extensa e simetricamente os tantos e, de outro modo, talvez dispersos sub-tópicos em pauta, um gesto estruturador dos saberes que veicula. Então, da relativa assistematicidade expositiva do De agri cultura catoniano ${ }^{15}$ a semelhantes cuidados reguladores da dispositio - os quais, por vezes, chegam mesmo a impor-se externos sobre os temas! $-{ }^{16}$ ao menos o De re rustica, tal como o divisamos com suas qualidades e defeitos, sequer de mais perto se furta à tentativa de um apresentar criterioso.

Sobre o papel do detalhamento numa obra dotada de características eminentemente técnicas, fazemos atentar para o cuidado de Varrão ao descrever, por exemplo, os bons espécimes de animais a buscar:

Devem ser belos de face, grandes, de olhos negros ou acastanhados, de narinas bem proporcionadas, de lábios fuscos ou avermelhados,

${ }^{14}$ Cf. Heurgon, J. Introduction. In: Varron. Économie rurale. Livre I. Texte établi, traduit et commenté par J. Heurgon. Paris: Les Belles Lettres, 2003, p. 46-47: On a vu déjà le plaisir qu'éprouvait Varron à des classifications qui lui permettaient de distribuer sa matière en groupes et sous-groupes bien equilibrés. Par exemple le livre 2 répartit la «res pecuaria» en trois parties, petit bétail, gros bétail et bétail improductif (mulets, chiens et bergers), mais chacune de ces parties est sub-divisée en neuf autres, 4 d'acquisition, 4 d'élevage, et une qui, concernant le nombre des têtes de bétail, est commune aux précédents: au total 81 subdivisions. Limportance de cette classification est telle aux yeux de Varron qu'il lui consacre son premier chapitre (2, 1, 11-28): Tremelius Scrofa, invoquécomme souverain expert, considère que son rôle se borne à l'exposer avant toutes choses. Puis, quand l'enquête a été ainsi délimitée (2,2,1: «limitata est pecuaria quaestio»), il laisse aux autres la tâche mineure de remplir les cadres ainsi tracés a priori.

${ }^{15}$ Cf. Trevizam, M. Linguagem e interpretação na Literatura agrária latina. Tese de doutoramento inédita. Campinas: IEL-UNICAMP, 2006, p. 60.

${ }^{16}$ Cf. Heurgon, op. cit., p. 47: Encore se heurte-t-il à une objection de principe d'Atticus $(2,1,25)$, qui, parce que les mulets ni les bergers ne peuvent être envisagés en tant qu'animaux reproducteurs, redoute que la troisième partie ne comporte deux lacunes. Varron intervient alors pour préciser que ses nombres ne sont pas susceptibles d'une exactitude mathématique, de même que les mille navires de la guerre de Troie ou les cent juges du tribunal des centumvirs. Tout de même, grâce au lait et au fromage, Scrofa ajoute deux fenêtres pour la symétrie $(2,1,28)$. 
nem arrebitados em cima nem pendentes embaixo, de queixo para dentro e com duas presas um pouco salientes saindo dele à direita $\mathrm{e}$ à esquerda, mais retos em cima que tortos, com os dentes afiados recobertos pelos lábios, de cabeças e orelhas grandes e de orelhas caídas, de nuca e colo espessos, de longas partes entre as junturas dos ossos, de pernas retas e de preferência voltadas para dentro que para fora, de patas grandes e largas que se abram quando anda, de dedos separados, de unhas duras e curvas, de sola nem córnea nem dura demais, mas como que cheia e mole; de corpo adelgaçado partindo das coxas, de coluna nem saliente nem curva, de cauda espessa, de latido forte, de grande mordedura, de preferência de cor branca, porque são mais facilmente reconhecidos nas trevas, e semelhantes ao leão. Além disso, deseja-se que as fêmeas tenham grandes úberes, de papilas iguais (minha tradução). ${ }^{17}$

A passagem acima, com efeito, trata de oferecer os traços físicos desejáveis nos cães que se adquirem para empregos variados nos fundi rustici - defesa da propriedade e dos bens do senhor, companhia, guarda dos rebanhos... -, de um modo, tanto quanto viável, exaustivo. Assim, nota-se, o escritor percorre os animais de um extremo a outro (do focinho à cauda, vale dizer), sem negligenciar a passagem por zonas intermediárias como o colo, as pernas, as patas, as unhas e o tronco. Além disso, há a menção à preferência pelo pelame claro e a especificidade anatômica feminina dos úberes.

Por outro lado, a zona anatômica da face surge especialmente bem trabalhada por Varrão: como que pausado em câmera lenta sobre a "documentação" desta parte específica dos cães, ele logra, assim, apresentar-lhe as características ideais dos olhos, das narinas, dos lábios, do "queixo" e das presas. Tais esforços representativos, de natureza, anacronismos à parte, quase "fotográfica", evidentemente se enquadram no projeto geral do autor de oferecer ao público eficazes diretrizes

\footnotetext{
${ }^{17}$ De re rustica II, IX, 3-5: Facie debent esse formosi, magnitudine ampla, oculis nigrantibus aut rauis, naribus congruentibus, labris subnigris aut rubicundis neque resimis superioribus nec pendulis subtus, mento suppresso et ex eo enatis duobus dentibus dextra et sinistra paulo eminulis, superioribus directis potius quam brocchis, acutos quos habeant labro tectos, capitibus et auriculis magnis ac flaccis, crassis ceruicibus ac collo, internodiis articulorum longis, cruribus rectis et potius uaris quam uatiis, pedibus magnis et latis, qui ingredienti ei displodantur, digitis discretis, unguibus duris ac curuis, solo ne ut corneo ne nimium duro, sed ut fermentato ac molli; a feminibus summis corpore suppresso, spina neque eminula neque curua, cauda crassa; latrato graui, hiatu magno, colore potissimum albo, quod in tenebris facilius agnoscuntur, specie leonina. Praeterea feminas uolunt esse mammosas aequalibus papillis.
} 
ordenadoras do maior número possível de afazeres rústicos. Nossas impressões a respeito são ainda reforçadas quando constatamos, no interior do mesmo livro II do De re rustica, a reiteração em grau e método, pelo menos, das descrições dos cavalos e caprinos. ${ }^{18}$

O último aspecto da tecnicidade da escrita que anunciamos acima, atinente a "não poupar" a paciência do público evitando o muito miúdo, "repulsivo" ou comezinho, presentifica-se no terceiro livro da obra através da substancial variedade dos sub-tópicos ali recobertos pela escrita. À maneira do que já fizemos com o De agri cultura de Catão, tomamos agora para parâmetro cotejador de esclarecimento o livro IV das Geórgicas de Virgílio: como é sabido dos leitores, ele se concentra, em estratégia francamente seletiva, no tema da apicultura, o qual se desdobra, por vias surpreendentes, no intrincado epýllion de Orfeu e Aristeu. Ora, a provável razão do poeta para assim proceder num poema didático não especificamente destinado a instruir para a lida agrária ${ }^{19}$ em princípio seria, aventamos, o intento de conferir maior (e mais fácil!) unidade ao livro derradeiro das Geórgicas. Além disso, as pequenas abelhas, em que pese à humildade do assunto, não são animais quaisquer: diligentemente organizadas em sociedade, devotadas ao "rei" da colmeia, capazes da guerra e do trabalho, por vezes risíveis, ${ }^{20}$ surgem na obra virgiliana em possível contraponto ao mundo humano; bem se entendem, pois, as razões práticas do poeta ao especializar-se assim e a tal ponto, nos limites do uno.

Em contrapartida, nada de exatamente semelhante ocorre nas páginas do livro III do De re rustica, obra que muitos pretendem "inspiradora" ${ }^{21}$ da posterior iniciativa poética de Virgílio: reina, nesse âmbito, sensível multiplicidade temática, em cobertura não só às espécies mais nobres da villatica pastio (caso dos pavões, dos arganazes e dos

${ }^{18}$ De re rustica II, VII e III.

${ }^{19}$ Cf. Dalzell, A. The criticism of didactic poetry. Essays on Lucretius, Virgil and Ovid. Toronto/ Buffalo/ London: University of Toronto Press, 1996, p. 106: What Wilkinson has in mind when he says that the "Georgics" masquerades as a didactic poem is that the didactic purpose is not the main purpose, or, if it is, the message is not quite what it appears to be.

${ }^{20}$ Cf. Dalzell, op. cit., p. 119: The picture of the tiny bees, described with all the earnestness of an ethnographic treatise, must surely be intended to raise a smile. The description of the battle of bees is the most obvious case of mock-heroic intent.

${ }^{21}$ Cf. Salvatore, A. "Georgiche" di Virgilio e "De re rustica" di Varrone. In: Atti del convegno virgiliano sul bimillenario delle "Georgiche". Napoli: 17-19 dicembre 1975. Napoli: Istituto Universitario Orientale, 1977, p. 79. 
peixes marinhos mantidos a vultoso custo para os donos), mas também às mais comuns, como simples galinhas e pombos. E, no interno dos sub-tópicos assim apresentados, assistimos à desenvolta abordagem miúda da reprodução e criação dos filhotes, da alimentação, dos viveiros, dos problemas possíveis (fugas, predadores, doenças...) e de como evitálos... Conforme a linha interpretativa que temos seguido para esta obra até o presente momento, simplesmente não faria sentido para um Varrão ocupado em instruir um público romano de ricos criadores para o melhor aproveitamento de suas terras negligenciar quaisquer ramos da uillatica pastio improdutivos sob o aspecto literário (mesmo que, na verdade, pombos ou tordos não se prestem tão bem quanto abelhas a paralelos com a dinâmica social humana) ou, apenas, por demais comezinhos para the merecerem o trabalho da pena: pelo contrário, o domínio identificado com essa parte da economia agrária antiga significou, nos tempos do autor, um meio especialmente seguro (e rico) de garantir a entrada de divisas nos bolsos do dominus. ${ }^{22}$

Um segundo eixo, alheio à tecnicidade, parece-nos contribuir decisivo para a diferenciação das imagens da ruralidade segundo as temos no De re rustica e no Cato Maior ciceroniano, como veremos: referimo-nos, desta vez, a certo aspecto de caráter francamente ideológico e identificado, na presente obra, com o que julgamos um maior nuançamento valorativo das mesmas. Explicando melhor, nota-se no De re rustica, ao lado do gesto instrutivo, a emissão de juízos sobre a vida e as práticas rurais, os quais se concentram, sobretudo, nas praelocutiones. Tais juízos, por falar de modo bastante simples sobre questões que divisamos, na verdade, complexas, em geral tendem para ressalvas aos hábitos "modernos" (com a pouca energia dos patres familias empregada no campo e o demasiado "amaciamento" da vida agrária pelas facilidades coevas) e a valorização dos antigos, quando, talvez, os romanos puderam corresponder melhor ao tipo humano do soldado-agricultor. ${ }^{23}$

Ocorre, no entanto, que as condições elogiadas por Varrão já há muito não correspondiam mais a um modelo viável de condução econômica das terras produtivas, ${ }^{24}$ ou mesmo dos nexos entre os ricos

${ }^{22}$ De re rustica III, II.

${ }^{23}$ Cf. tipicamente praelocutio do De agri cultura, de Catão Censor.

${ }^{24}$ Cf. Trevizam, op. cit., p. 18-19. 
proprietários e um ambiente onde, todavia, sentiam-se ainda ${ }^{25}$ material e ideologicamente "ancorados". Esse descompasso se reflete na obra, sobretudo, pela presença do livro II, cujo direcionamento prático antes condiz com o "novo" viés da criação em larga escala (e até em concorrência por espaço com as terras agrícolas!), ${ }^{26}$ e do livro III, cujos produtos, tantas vezes, para nada serviam a não ser suprir a exigente demanda dos citadinos por itens de luxo.

Outro aspecto, por sua vez, não negligenciável para o exame da mesma questão corresponde a certos usos a que as elites romanas de fins da república destinaram o ambiente rústico: espaço habitual, sintomaticamente, de um otium compreendido como afastamento das grandes obrigações coletivas, amiúde se transfigurou em mero simulacro da vida urbana, com todas as comodidades desejáveis. O caso das edificações rústicas, com tantos exemplos de questionável utilidade prática, presta-se a ilustrar com clareza a face da "domesticação" de um campo tornado apenas mais um cenário para refinados prazeres: a praelocutio de De re rustica II, assim, critica a verdadeira mania dos contemporâneos de construírem e nomearem à grega os recintos em suas terras; em De re rustica III, no entanto, o sofisticado aviário de Varrão em Casino, o qual se presta ao deleite de convivas humanos, mostra-nos o próprio autor das críticas a incorrer na mesma "falta" que antes imputara aos concidadãos: não se chama, inclusive, tholos à grega a parte circular do edifício?

Em outras palavras, se por "ruralidade" entendemos o conjunto do imaginário e das práticas conduzidas pelos antigos romanos em ambiente não-urbano, claro está que os diálogos rerum rusticarum de Varrão não só explicitam, sob cores ideologizantes, "boas"/ tradicionais e "más"/ "modernas" faces da mesma como, ainda, a própria "voz" autoral presente no texto oscila entre criticar... ou endossar segura quaisquer inovações neste tradicionalíssimo plano da vida antiga.

\footnotetext{
${ }^{25}$ Cf. Grimal, P. Virgílio, ou o segundo nascimento de Roma. Tradução de Ivone Castilho Benedetti. São Paulo: Martins Fontes, 1992, p. 141: Uma lei que datava dos anos que precederam a guerra contra Aníbal proibia que os senadores possuíssem navios que excedessem certa tonelagem: a necessária para evacuar por mar os produtos de suas propriedades da Etrúria, da Campânia e da Apúlia, não mais.

${ }^{26}$ Cf. Sabattini, A. Sulla transumanza in Varrone. Athenaeum. Studi periodici di Letteratura e Storia dell'Antichità. Pavia, vol. LV, fasc. I-II, p. 201, 1977.
} 


\section{As especificidades do tratamento ciceroniano da ruralidade no Cato Maior}

O tratamento da ruralidade no interno do Cato Maior de Cícero apresenta especificidades que, julgamos, justificam a apresentação dos traços gerais de toda a obra antes de passarmos aos comentários pontualmente ditos. Assim, desta vez deparamos um diálogo com a absoluta prevalência da personagem-título ao expor doutrinas que logo se revelam biograficamente consolatórias, pensando no fato de sua dedicação a um também sexagenário Ático ${ }^{27}$ e na situação pessoal de Cícero na data de compô-lo. ${ }^{28} \mathrm{O}$ assunto da mesma "consolação" corresponde a dissuadir Lélio e Cipião Emiliano, os imediatos destinatários fictícios da lição filosófica oferecida, da crença em alguns "inevitáveis" males da velhice, quais sejam, a- a inércia, b- a falta de vigor, c- o pleno alheamento aos prazeres e d- a proximidade da morte.

Para cada um desses impedimentos às chances de felicidade humana na fase derradeira da vida, portanto, a personagem de Catão Censor oferece sucessiva objeção, ${ }^{29}$ visando, nos termos acima vistos, a propor uma imagem da velhice contrária aos maus estereótipos do senso-comum. Consideramos fundamental, para a eficácia da estratégia "pedagógica" assim constituída, o fato de que o expositor responsável por ela seja justo Catão: de fato, vemo-nos aqui diante de uma figura-chave do antigo ideário latino sobre a própria cultura, pois ele soube, como poucos, "encarnar" (ou, imaginariamente, assumir) ${ }^{30}$ os traços do romano à maneira antiga. Nascido de família de cavaleiros (equites) nos campos sabinos (234 a.C.), teria trabalhado a terra com as próprias mãos em

${ }^{27}$ Cf. Narducci, E. Il "Cato Maior", o la vecchiezza dell'aristocrazia romana. Quaderni distoria. Anno VIII, n. 16, p. 121-122, 1982.

${ }^{28}$ Cf. Robert, J.-N. Introduction. In: Cicéron. De la vieillesse. Texte établi et traduit par Pierre Wuilleumier, introduction, notes et annexes de Jean-Noël Robert. Paris: Les Belles Lettres, 2003, p. 9: Politiquement, il souffre d'être tenu à l'écart des affaires. Courant mai - 45, après la victoire de Munda, il décide d'écrire à César pour lui donner quelques conseils, comme cela se fait couramment à cette époque (Salluste fera de même). Mais des amis du nouveau maître de Rome lui déconseillent vivement d'envoyer sa lettre pour éviter les foudres césariennes. Cicéron, dépité, sent poindre le tyran sous l'armure du dictateur.

${ }^{29}$ Cato Maior, 15-85.

${ }^{30}$ A caracterização de Catão neste diálogo de Cícero, de modo algum, corresponde sempre aos contornos da personalidade histórica retratada: ele surge, aqui, bem mais humanus e letrado do que jamais teria sido "na vida real", avisam-nos os críticos (cf. de Saint-Denis, E. Caton l'ancien vu par Cicéron. Linformation littéraire. Paris, année VIII, n. 1, p. 93-100, 1956). 
sua primeira juventude antes de precoces inícios como militar, orador e magistrado e de galgar, aos 39 anos, o posto de cônsul da república romana; sem cessar as contribuições à pátria depois de atingido o auge do cursus honorum, vemo-lo investido da censura em 184 a.C., a qual soube desempenhar com lendária rigidez.

Embora, na "fase" que se seguiu à censura, não mais tenha tido representatividade em magistratura alguma, Catão continuou influente sobre o senado e severo opositor de ideias consideradas deletérias do tecido social republicano: atribui-se-lhe, mesmo, a famosa iniciativa de expulsar certos filósofos gregos de Roma (155 a.C.), entre os quais se contavam Carnéades, Diógenes e Critolau. ${ }^{31}$ Além disso, até o término de sua longeva existência (149 a.C.), ele, que se iniciara numa vigorosa oratória desde moço, dedicou-se a escrever obras de cunho formador, ora destinadas a instruir seus concidadãos, ora o filho de seu primeiro casamento, Marco Pórcio Catão Liciniano: incluem-se no primeiro grupo textos como as Origines, das quais se lembra Varrão em De re rustica, o De re militari e o De agri cultura, peça inaugural da prosa romana no século II a.C.; no segundo, o Ad filium, identificado, na opinião de Astin, com variadíssima coletânea de preceitos práticos. ${ }^{32}$

Pelo breve resumo biográfico sobre a personagem, já se deduz, pois, que sua escolha por Cícero para presidir o Cato Maior manifesta, além dos intentos políticos notados por Jean-Noël Robert, ${ }^{33}$ traços francamente exemplares, no melhor espírito da tradição romana. ${ }^{34}$ Tudo ocorre como se, ao compor esta obra votada a fins éticos, no sentido do correto direcionamento para a conduta humana, o autor tivesse privilegiado ceder a voz a uma figura amiúde associável, no ideário antigo, a aspectos positivos: então, certas constantes morais catonianas

${ }^{31}$ Cf. Robert, J.-N. Caton ou le citoyen. Paris : Les Belles Lettres, 2002, p. 282-286.

${ }^{32}$ Cf. Astin, A. E. Cato the Censor. Oxford: Clarendon Press, 1978, p. 183.

${ }^{33}$ Cf. Robert, op. cit., 2003, p. 11: Ne doutons pas, enfin, que ce Caton ait, pour Cicéron, une visée politique. Le traité résonne aussi comme une ultime contradiction à César, portée par un homme qui incarna, en son temps, la République et qui, pourl'auteur, illustre parfaitement l'anti-César.

${ }^{34}$ Em muitas práticas de sua vida social (como, sobretudo, na oratória), os romanos antigos costumaram evocar os exempla Maiorum a fim de fundamentar ou dissuadir moralmente de condutas; no Cato Maior, curiosamente, em espécie de procedimento de mise-en-abîme, Catão mesmo evoca saudoso a figura senil de Quinto Fábio Máximo Cunctator ("O Temporizador", morto em 203 a.C.), por cinco vezes cônsul e responsável bélico pela retomada de Tarento durante as Guerras Púnicas; a ele, Catão conhecera, quando jovem, já velho, vindo, porém, a amá-lo, por suas qualidades, "como a um companheiro" (ut aequalem, 10). 
como a energia, a persistência e a atividade até o fim por si só imbuem tais lições morais da auctoritas afeita a cativar o público e a tornar persuasiva uma estratégia de condescendente olhar sobre a velhice.

Também se nota, pelo que dissemos do conteúdo e propósitos deste diálogo, que evidentemente não divisamos aqui um texto - à diferença do de Varrão antes analisado - "a respeito" da ruralidade, mas que, de modo específico, acaba por incorporá-la a um panorama e a fins mais amplos. Fazemos ver, nesse sentido, que os temas vinculados à agricultura ou à experiência humana na terra adentram duas vezes as linhas do Cato Maior, correspondendo a primeira a um desdobramento refutatório no âmbito da atividade do senex (ou seja, para corroborar que o homem velho não deve, necessariamente, permanecer inerte, por sempre poder ocupar-se dos campos - 24-25) e a segunda (51-60) a outro, no dos prazeres ainda possíveis.

Ambas as "intromissões" do tema rural na obra - decerto, não pouco motivadas pelo "salutar" ${ }^{35}$ tradicionalismo do assunto e pelo fato de Catão, como se sabe, ser o autor de uma obra técnica agrária - recebem particulares tratamentos no interno da obra. Assim, acompanham ali as atividades agrícolas (24-25) o empenho político (15-20), o intelectual (21-23) e o educativo no contato com os mais jovens (25-26); quanto aos prazeres do campo (51-60), intercalam-se no corpo textual aos tópicos dos perigos dos deleites físicos (39-44), da conservação dos mesmos (44-48), da superioridade do deleite intelectual (49-50), do prestígio da velhice (6164) e dos defeitos de personalidade apenas de algum eventual ancião (65-66). ${ }^{36}$ Além da inserção do sub-tópico dos prazeres do campo num entorno refutatório mais rico, ${ }^{37}$ ele também recebe maior desenvolvimento quando em si mesmo considerado.

Dessa forma, o que se diz em 24-25 corresponde, basicamente, apenas ao relato de Catão sobre ter testemunhado, no país sabino, seus

${ }^{35}$ Cf. Miles, G. B. Virgil's “Georgics”. A new interpretation. Berkeley/ Los Angeles: University of California Press, 1980, p. 7.

${ }^{36}$ Para todas estas indicações numéricas de partes, seguimos a divisão de Pierre Wuilleumier, segundo esquema reproduzido à página 25 da edição do Cato Maior preparada e traduzida por ele e prefaciada/ anotada por Jean-Noël Robert (cf. supra nota 27).

${ }^{37}$ Cf., sobre a grande importância do tema do prazer (e positivamente considerado!) no Cato Maior, algo paradoxal num filósofo que muitas vezes se pretendeu "inimigo" dos epicuristas, nuançadoras considerações de François Prost [Le thème du plaisir dans le "Cato Maior": aspects philosophiques. In: Galand-Hallyn, P.; Lévy, C.; Verbaal W. (org.). Le plaisir dans l'Antiquité et à la Rennaissance. Turnhout: Brepols Publishers, 2008, p. 378]; pessoalmente, sou grato ao autor pela disponibilização deste artigo e pelas gentis indicações bibliográficas sobre Cícero. 
vizinhos romanos de alguma idade a jamais faltarem no acompanhamento dos principais afazeres da lida agrícola (como a semeadura, a colheita e a estocagem dos frutos da terra); embora, pelo modo como se expressa tal "acompanhamento" - por um discreto ablativo absoluto, quibus absentibus -, pudéssemos, em princípio, pensar que tais senes sabinos participariam dos trabalhos em mera supervisão à atividade alheia, sua presença mais direta parece implicada depois, quando se menciona, ao final do sub-tópico, virem eles até a cultivar para proveito alheio (quaerenti cui serat - "a quem pergunta para quem planta"), pois, talvez, não mais estejam vivos quando chegarem os frutos de seus esforços.

A mais longa passagem correspondente a 51-60, por sua vez, desdobra-se complexa e, até, belamente lírica em sucessivos pontos que vale a pena apontar. Inicialmente, é sintomático das colorações filosóficas da abordagem do tema no âmbito do Cato Maior que a personagem de Catão chegue a estabelecer afinidades entre a vida do agricultor e a do sábio [quae nec ulla impediuntur senectute et mihi ad sapientis uitam proxume uidentur accedere - "eles (uoluptates = "os prazeres") por velhice alguma são barrados e parecem-me proximamente coadunar-se à vida do sábio"]; a terra, ainda, em léxico de todo evocativo dos mundos do poder e do dinheiro, numquam recusat imperium nec umquam sine usura reddit quod accepit, sed alias minore, plerumque maiore cum fenore ("nunca recusa uma ordem nem jamais devolve sem juros o que recebeu, mas às vezes com menor, quase sempre com maior lucro") e, de modo por inteiro ilustrativo do peculiar direcionamento de sentidos dado ao tema por Cícero (não, de fato, técnico para os fins que aqui nos dizem respeito), não interessa a Catão apenas materialmente:

Contudo, decerto gosto não só do fruto, mas ainda do vigor da própria terra e de sua natureza: quando acolheu a semente esparsa no interior macio e lavrado, primeiro a mantém encoberta (occaecatum), e por isso se chamou de occatio ("gradadura") o que o faz -, depois, abafada pelos vapores e por sua pressão, dilata e tira dela o verdor da erva, o qual, apoiando-se nas raízes do broto, aos poucos se desenvolve; e, de pé com a haste nodosa, já se implica em dobras como que atingindo a puberdade. Quando as deixa, espalha os grãos bem arranjados da espiga e resguarda-se contra os bicos das aves menores com a proteção das arestas (minha tradução). ${ }^{38}$

\footnotetext{
${ }^{38}$ Cato Maior, 51: Quamquam me quidem non fructus modo, sed etiam ipsius terrae uis ac natura delectat: quae cum gremio mollito ac subacto sparsum semen excepit, primum id occaecatum cohibet, ex quo occatio quae hoc efficit nominata est -, dein tepefactum uapore et compressu suo diffundit et elicit herbescentem ex eo uiriditatem, quae nixa fibris stirpium, sensim adulescit, culmoque erecta geniculato, uaginis iam quasi pubescens includitur; ex quibus cum emersit, fundit frugem spici ordine structam, et contra auium minorum morsus munitur uallo aristarum.
} 
Ora, o que temos acima, na verdade identificado com uma literal declaração de amor da personagem à terra pelo maravilhoso de sua força geradora mesma, de modo algum assume o viés discursivo do preceituar, mas, antes, o de uma espécie de justificativa pelo entusiasmo em jogo. Desperta especialmente o interesse a proposição de inegável proximidade entre o processo de fecundação e crescimento das plantas no seio da terra e o que se dá, de modo paralelo, com as "crias" humanas: concretas imagens como a da acolhida da "semente" (semen) num "interior macio" (gremio mollito), da saída, gradual fortalecimento, puberdade (quasi pubescens) e, enfim, madureza do broto em algo a poder, de pé, defender-se com as arestas da casca e dar ele mesmo seus próprios grãos estabelecem claros nexos com nossa natureza.

$\mathrm{Na}$ sequência (52), ao mencionar as vantagens da vinha para um velho agricultor, Catão continua alheio a imediatas constatações de ganho material (algo bem diverso se passava pela escala de valores traçada nas linhas do De agri cultura do autor), ${ }^{39}$ como se, ainda, novo espetáculo de maravilhas o aguardasse a propósito da dedicação a essa cultura: tal sentimento se patenteia, por exemplo, ao destacar a personagem os "esforços" da planta para erguer-se do chão com as gavinhas (clauiculis suis quasi manibus quidquid est nacta complectitur - "com suas gavinhas, à semelhança de mãos, agarra o que quer que tenha encontrado"), sua "selvagem" ${ }^{40}$ exuberância ao dar ramos (ne... in omnis partis nimia fundatur - "para não... por todos os lados, em excesso, espalhar-se") e a beleza dos pés já carregados de uvas que pâmpanos protegem do sol (qua quid potest esse cum fructu laetius, tum aspectu pulchrius? - "o que pode ser mais alegre, pelo fruto, que isso, o que mais bonito pela aparência?”).

Ao início de 54, depois de omitir-se de tratar de um tema tão banal quanto a adubação da terra (quid de utilitate loquar stercorandi? Dixi in eo libro quem de rebus rusticis scripsi - "por que falaria da utilidade de adubar? Já o disse naquele livro que compus dos assuntos rurais"), um mais polido e literato Catão lembra o apagamento do assunto n'Os

\footnotetext{
${ }^{39}$ Cf. Marmorale, E. Cato Maior. Bari: Laterza \& Figli, 1949, p. 184-185: Catão, pelo contrário, decerto não o teria sabido fazer; a planta nada é para ele a não ser algo de que é preciso cuidar para obter bons frutos, o animal nada a não ser um instrumento de trabalho. Também quando fala deflores e de plantas de jardim, nunca usa um adjetivo que indique uma descrição ou um sentimento: aquelas plantas e aquelas flores são vistas sob o aspecto utilitário, porque Catão sabe que delas deve sair o dinheiro necessário para o sustento de uma família (minha tradução do original italiano).

${ }^{40}$ Em Geórgicas II, 362-370, Virgílio também apresenta uma imagem das videiras como "indisciplinadamente" desejosas de crescer e necessitando, assim, serem refreadas pelo agricola.
} 
trabalhos e os dias de Hesíodo e que Laertes, pai de Ulisses na Odisseia, costumava consolar as dores da ausência do filho justamente estercando os campos (XXIV, 226), longe da violência palaciana dos pretendentes. Nos dois seguimentos posteriores, o cenário é dominado pelos emblemas de lendários anciãos romanos, para quem lavrar o solo nunca significou desonra ou afastamento das responsabilidades cívicas (Mânio Cúrio Dentato, triunfador sobre os sabinos, os samnitas e o rei Pirro, em 275 a.C., e o ditador Cincinato - séc. V a.C.), bem como pela enumeração de importantes vantagens da lida rústica, quais sejam, não faltar às obrigações para com o gênero humano, ter fartura de víveres e de itens votivos aos deuses; cumprindo-se o bem da fartura, inclusive, o agricola mais uma vez se vê acordado com a uoluptas (in gratiam iam cum uoluptate redeamus - "tornemos já às boas-graças do prazer").

$\mathrm{O}$ que vemos em 57 e 58 poder-se-ia respectivamente resumir como uma entrega quase sensual a algumas delícias da vida rústica (como a harmonia "paisagística" dos olivais, vinhedos e arvoredos bem plantados e o gozo simples das sombras ou do fogo conforme faça calor ou frio) e a serena recusa dos deleites das armas, dos cavalos, da caça e outros, mais bem acomodados à juventude. A penúltima passagem, toda ela adaptada de antológico trecho do Econômico de Xenofonte (IV, 20ss.), mereceria estendidos comentários pela complexidade das questões que envolve no tocante à interface entre a cultura grega e a latina: sem nos alongarmos nesse sentido, por ora limitamo-nos a lembrar que se trata da anedota da visita ao jovem Ciro pelo general lacedemônio Lisandro. Ora, nessa ocasião, o segundo tivera a oportunidade de ser recebido num belíssimo e fecundo horto - sugestivamente chamado, à maneira oriental, parádeisos - pelo também belo príncipe persa, acrescendo-se a todas as boas impressões recebidas... que o jardim fora cultivado pelas mãos do próprio Ciro. ${ }^{41} \mathrm{E}$, em reconhecimento a uma excelência, também agrária, do príncipe, apenas restou ao espartano dizer:

Com muita justiça, Ciro, dizem-te feliz, pois foi unida a sorte a teu valor (minha tradução). ${ }^{42}$

Enfim, o trecho se acaba com o novo exemplum de Marco Valério Corvino, a quem a tradição atribuía ter-se ocupado de seus campos até

\footnotetext{
${ }^{41}$ Econômico, IV, 23-25.

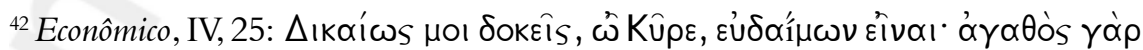

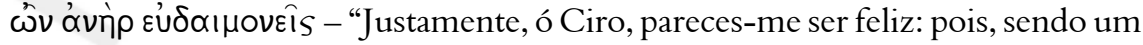
homem bom, és feliz" (minha tradução). Cf. também, para a versão latina, Cato Maior, 59: Rite uero te, Cyre, beatum ferunt, quoniam uirtuti tuae fortuna coniuncta est.
} 
a morte, com mais de cem anos. Cônsul por seis ocasiões, quase meio século separou-lhe a primeira da última vez nessa magistratura; ${ }^{43}$ ainda, a personagem de Catão o dá, aqui, por mais feliz na velhice, quando só viu aumentar o "prestígio" (auctoritas) e diminuírem (publicamente) os "trabalhos" (labores).

A recapitulação feita de alguns dos principais elementos dos prazeres (ou labores) ${ }^{44}$ da agricultura no Cato Maior não deixa dúvidas de que, na verdade, encontramo-nos desta feita bem afastados de qualquer abordagem técnica da ruralidade: faltam, nos termos do dito, o comprometimento com os detalhes, com a sistematicidade e com uma prática "dureza" expositiva. Do ponto de vista da sistematicidade ao abordar as práticas rurais, embora Catão cite de passagem as vinhas, os grãos, a grande criação animal, a apicultura e, até, algum produto dos hortos (florum omnium uarietate - "com a variedade de todas as flores" - 54), ou seja, acabe de certo modo abrangendo, como no De re rustica varroniano, os principais ramos da economia agrária antiga, trata-se de meras menções, nunca de livros inteiros... No interno de cada uma dessas citações, ainda, não se trata de forma alguma, mesmo no caso das mais desenvolvidas (como aquela às vinhas e a acima transcrita, aos grãos), de enumerar e bem descrever "todas" as etapas dos trabalhos, como se, aqui, sequer fosse possível conceber um mecanismo construtivo afim ao esboço e posterior preenchimento das "grades" estruturadoras encontradas no De re rustica.

Por outro lado, se algum detalhamento há, por exemplo, ao apontar em 52-53 vários motivos do encanto natural das vinhas - natura ipsa delectat, "a natureza mesma me cativa" -, como seus esforços para porem-se de pé, sua pujança ao crescerem e a beleza dos ramos já carregados de cachos, nada se compara em grau e, até, reiteração, aos cuidados do autor do De re rustica quando se ocupa de apresentar-nos, sob o aspecto visto há pouco, a anatomia dos animais desejáveis no fundus. E, há que se convir, pouquíssima aspereza ou trivialidade, pelo modo mesmo de apresentar o tema, encontramos nas menções agrárias do Cato Maior: segundo indiciado pelo excerto referente ao juízo crítico de Powell, que ajuda a abrir o artigo, talvez se concentrem nos "humildes"

\footnotetext{
${ }^{43}$ Cf. nota de J.-N. Robert ao trecho, na edição citada do Cato Maior ciceroniano.

${ }^{44}$ As ressalvas que fazemos abaixo sobre a ausência da tecnicidade agrária no trecho dos "prazeres da agricultura" do Cato Maior também se aplicam àquele brevíssimo das "atividades", esse último, por sinal, bem menos desenvolvido em vários aspectos, como assinalamos.
} 
trechos rurais os mais sensíveis acentos "líricos" de todo o diálogo; ${ }^{45}$ tal lirismo, parece-nos, coaduna-se com a evidenciação de aspectos maravilhosos até nos mais banais ou "pequenos" fenômenos a desenrolar-se sem cessar no mundo à nossa volta. ${ }^{46}$

Sobre a questão valorativa de uma atividade/ prazer peculiar como o da agricultura, já que, pela estrutura do diálogo, vemo-los sempre inseridos na refutação das queixas contra a velhice, evidentemente não faria sentido a polemização interna em torno de ser ou não irrestrito bem a ruralidade. O próprio prestígio do tema numa cultura como a romana antiga, promotora da ideologia da "moralidade camponesa", e, por séculos, ciosa dos elos entre os membros das famílias tradicionais e a terra, ${ }^{47}$ reveste nobremente o assunto. Ademais, como atividade e prazer vêm contrapor-se, justamente, aos males da suposta inércia senil e do fim de todos os deleites no tempo derradeiro da existência humana, é forçoso, para consolar e desfazer tais imagens, que se construam visões convidativas da vida no campo: assim, evitando ressaltar-lhe eventuais degradações "modernizantes" ou os esperados embrutecimentos da lida quotidiana - óbvio aspecto do verdadeiro tratado agrícola de Catão Censor! -, ${ }^{48}$ Cícero logra oferecer da ruralidade um quadro, ao mesmo tempo, afim ao honestum e luminoso.

Tal "linearidade" valorativa, no entanto, bem como a ausência de uma real tecnicidade agrícola, jamais colocaria em desvantagem as qualidades literárias ou filosóficas do Cato Maior, diante do De re rustica: trata-se, no cotejo com a obra varroniana que aqui temos em mira, de uma iniciativa diversa, de todo bem-sucedida nos propósitos-outros a que Cícero a votou. E, como atesta a fortuna da obra nos tempos subsequentes, ${ }^{49}$ de modo algum abordar também a ruralidade, mas à sua peculiar maneira, foi então desdouro para a pena de Cícero.

\footnotetext{
${ }^{45}$ Cf. supra nota 5.

${ }^{46}$ Não por acaso, a produção do "estranhamento" na percepção de um mundo "desautomatizado" tem sido veiculada por vários críticos (Viktor Chklovski - 1917, Roman Jakobson, Terry Eagleton - 1983) como central para a própria poeticidade da linguagem. Cf. Teixeira, I. O formalismo russo. Cult. São Paulo, p. 36-39, agosto 1998.

${ }^{47}$ Cf. supra nota 23.

${ }^{48}$ Cf. supra nota 36.

${ }^{49}$ Cf. MacKendrick, P. On old age. In: . The philosophical books of Cicero. London: Duckworth, 1995, p. 212: The survival of so many manuscripts attests to the work's popularity through the centuries. The noble sentiments and beautiful prose also made "On old age" a standard school text.
} 


\section{Referências}

ASTIN, A. E. Cato the Censor. Oxford: Clarendon Press, 1978.

CATO; VARRO. On agriculture. With an English translation by H. D. Hooper. Cambridge, Mass./ London, England: Harvard University Press, 1999.

CICÉRON. De la vieillesse. Texte établi et traduit par Pierre Wuilleumier, introduction, notes et annexes de Jean-Noël Robert. Paris: Les Belles Lettres, 2003.

COLUMELLA. On agriculture. With an English translation by E. S. Forster and E. H. Heffner. Cambridge, Mass./ London: Harvard University Press, 1954. Vol. III.

DALZELL, A. The criticism of didactic poetry. Essays on Lucretius, Virgil and Ovid. Toronto/ Buffalo/ London: University of Toronto Press, 1996.

GRIMAL, P. Virgílio, ou o segundo nascimento de Roma. Trad. Ivone Castilho Benedetti. São Paulo: Martins Fontes, 1992.

HEURGON, J. Introduction. In: VARRON. Économie rurale. Livre I. Texte établi, traduit et commenté par J. Heurgon Paris: Les Belles Lettres, 2003, p. 7-85.

MAC KENDRICK, P. On old age. In: . The philosophical books of Cicero. London: Duckworth, 1995.

MARMORALE, E. Cato Maior. Bari: Laterza \& Figli, 1949.

MARTIN, R. Recherches sur les agronomes latins et leurs conceptions économiques et sociales. Paris: Les Belles Lettres, 1971.

MILES, G. B. Virgil's "Georgics". A new interpretation. Berkeley/Los Angeles: University of California Press, 1980.

de MONTAIGNE, M. Essais. Londres: Jean Nourse \& Vaillant, 1768. Vol IV.

NARDUCCI, E. Il “Cato Maior”, o la vecchiezza dell'aristocrazia romana. Quaderni distoria. Anno VIII, n. 16, p. 121-163, 1982.

PERUTELLI, A. Il texto come maestro. In: CAVALLO, G. et alii. (Org.). Lo spazio letterario di Roma antica. Roma: Salerno Editrice, 1989. Vol. I, p. 277-310.

POWELL, J. G. F. Introduction. In: CICERO. Cato Maior de Senectute. Edited with introduction and commentary by J. G. F. Powell. Cambridge: University Press, 1988, p. 1-30ss.

PROST, F. Le thème du plaisir dans le "Cato Maior": aspects philosophiques. In: GALAND-HALLYN, P.; LÉVY, C.; VERBAAL W. (Org.). Le plaisir dans l'Antiquité et à la Rennaissance. Turnhout: Brepols Publishers, 2008, p. 377-394.

ROBERT, J.-N. Caton ou le citoyen. Paris: Les Belles Lettres, 2002.

ROBERT, J.-N. Introduction. In: CICÉRON. De la vieillesse. Texte établi et traduit par Pierre Wuilleumier, introduction, notes et annexes de Jean-Noël Robert. Paris: Les Belles Lettres, 2003, p. 7-25. 
ROBERT, J.-N. La vie à la campagne dans l'antiquité romaine. Paris: Les Belles Lettres, 1985.

RUCH, M. Le préambule dans les oeuvres philosophiques de Cicéron. Essai sur la genèse et l'art du dialogue. Paris: Les Belles Lettres, 1958.

SABATTINI, A. Sulla transumanza in Varrone. Athenaeum. Studi periodici di Letteratura e Storia dell'Antichità. Pavia, v. LV, fasc. I-II, p. 199-203, 1977.

de SAINT-DENIS, E. Caton l'ancien vu par Cicéron. L'information littéraire. Paris, année VIII, n. 1, p. 93-100, 1956.

SALVATORE, A. "Georgiche" di Virgilio e "De re rustica" di Varrone. In: Atti del convegno virgiliano sul bimillenario delle "Georgiche”-Napoli: 17-19 dicembre 1975. Napoli: Istituto Universitario Orientale, 1977, p. 67-111.

TEIXEIRA, I. O formalismo russo. Cult. São Paulo, p. 36-39, agosto 1998.

TREVIZAM, M. Linguagem e interpretação na literatura agrária latina. Tese (Doutorado). Campinas: IEL-UNICAMP, 2006. (Inédita).

VARRON. Économie rurale. Livre I. Texte établi, traduit et commenté par J. Heurgon Paris: Les Belles Lettres, 2003.

VARRON. Économie rurale. Livre II. Texte établi, traduit et commenté par C. Guiraud. Paris: Les Belles Lettres, 2003.

VARRON. Économie rurale. Livre III. Texte établi, traduit et commenté par C. Guiraud. Paris: Les Belles Lettres, 1997.

VIRGILE. Géorgiques. Texte traduit par E. de Saint-Denis. Introduction, notes et postface de J. Pigeaud. Paris: Les Belles Lettres, 1998.

XENOPHON. Oeconomicus. A social and historical commentary. Translation, introduction and commentary by Sarah B. Pomeroy. Oxford: Clarendon Press, 1995. 